Article

\title{
Application of Neural Network and Time-Domain Feature Extraction Techniques for Determining Volumetric Percentages and the Type of Two Phase Flow Regimes Independent of Scale Layer Thickness
}

\author{
Abdullah K. Alanazi ${ }^{1}{ }^{(D)}$, Seyed Mehdi Alizadeh ${ }^{2}$, Karina Shamilyevna Nurgalieva ${ }^{3}{ }^{(D)}$, Slavko Nesic $^{4}$, \\ John William Grimaldo Guerrero ${ }^{5, * \mathbb{D}}$, Hala M. Abo-Dief ${ }^{1}$, Ehsan Eftekhari-Zadeh ${ }^{6, *(\mathbb{D})}$, Ehsan Nazemi ${ }^{7}$ (D) \\ and Igor M. Narozhnyy ${ }^{8}$
}

check for

updates

Citation: Alanazi, A.K.; Alizadeh, S.M.; Nurgalieva, K.S.; Nesic, S.; Grimaldo Guerrero, J.W.; Abo-Dief, H.M.; Eftekhari-Zadeh, E.; Nazemi, E.; Narozhnyy, I.M. Application of Neural Network and Time-Domain Feature Extraction Techniques for Determining Volumetric Percentages and the Type of Two Phase Flow Regimes Independent of Scale Layer Thickness. Appl. Sci. 2022, 12, 1336. https://doi.org/10.3390/ app12031336

Academic Editor: Liangxing Li

Received: 27 December 2021

Accepted: 24 January 2022

Published: 27 January 2022

Publisher's Note: MDPI stays neutral with regard to jurisdictional claims in published maps and institutional affiliations.

Copyright: (c) 2022 by the authors Licensee MDPI, Basel, Switzerland. This article is an open access article distributed under the terms and conditions of the Creative Commons Attribution (CC BY) license (https:// creativecommons.org/licenses/by/ $4.0 /)$.
1 Department of Chemistry, Faculty of Science, Taif University, P.O. Box 11099, Taif 21944, Saudi Arabia; aalanaz4@tu.edu.sa (A.K.A.); h.abodeif@tu.edu.sa (H.M.A.-D.)

2 Petroleum Engineering Department, Australian College of Kuwait, West Mishref 13015, Kuwait; s.alizadeh@ack.edu.kw

3 Department of Development and Operation of Oil and Gas Fields, Saint-Petersburg Mining University, 199106 Saint-Petersburg, Russia; khaibullina_k@mail.ru

4 Faculty of Technology, University of Novi Sad, 21000 Novi Sad, Serbia; slavko.nesic@nis.rs

5 Department of Energy, Universidad de la Costa, Barranquilla 080001, Colombia

6 Institute of Optics and Quantum Electronics, Friedrich-Schiller-University Jena, Max-Wien-Platz 1, 07743 Jena, Germany

7 Imec-Vision Laboratory, Department of Physics, University of Antwerp, 2610 Antwerp, Belgium; ehsan.nazemi@uantwerpen.be

8 Department of Commercialization of Intellectual Activity Resultse Center for Technology Transfer of RUDN University, Mining Oil and Gas Department, RUDN University, 117198 Moscow, Russia; narozhnyy-im@rudn.ru

* Correspondence: jgrimald1@cuc.edu.co (J.W.G.G.); e.eftekharizadeh@uni-jena.de (E.E.-Z.)

\begin{abstract}
One of the factors that significantly affects the efficiency of oil and gas industry equipment is the scales formed in the pipelines. In this innovative, non-invasive system, the inclusion of a dual-energy gamma source and two sodium iodide detectors was investigated with the help of artificial intelligence to determine the flow pattern and volume percentage in a two-phase flow by considering the thickness of the scale in the tested pipeline. In the proposed structure, a dual-energy gamma source consisting of barium-133 and cesium-137 isotopes emit photons, one detector recorded transmitted photons and a second detector recorded the scattered photons. After simulating the mentioned structure using Monte Carlo N-Particle (MCNP) code, time characteristics named 4th order moment, kurtosis and skewness were extracted from the recorded data of both the transmission detector (TD) and scattering detector (SD). These characteristics were considered as inputs of the multilayer perceptron (MLP) neural network. Two neural networks that were able to determine volume percentages with high accuracy, as well as classify all flow regimes correctly, were trained.
\end{abstract}

Keywords: artificial intelligence; feature extraction; scale thickness; two-phase flow; MLP neural network

\section{Introduction}

In addition to the gamma radiation efficiency technique, which is the basis of this study, there are other techniques, such as hydrostatic, ultrasonic, and hydrometric techniques, that are used to distinguish the flow regime and volume fraction of multiphase flow. The answer to the fundamental question of what the benefit of is implementing a non-invasive method to determine the mentioned parameters can be explained in several parts. 
(A) One of the requirements for optimizing the separation process in the oil and gas industry is to have quantitative and sufficient information about the volume fraction of the gas and oil phases.

(B) Understanding the type of flow pattern along with determining the volume fraction of gas and oil phases is a requisite of transfer processes because it is straightforwardly related to a large part of the project economy.

(C) The efficiency of the separation process is highly influenced by the type of flow regime.

(D) Whether the drilling process should continue or stop at any time can only be determined by understanding the volume fraction of each component.

One of the studies conducted years ago to flow metering and determine volume percentage was a study published in 1999 by Abro et al. [1]. Determination of void fraction was done by Abro et al. using low-energy gamma-ray Americium-241 instead of the traditional Caesium-137 source. They tried to determine which detector positions best serve the purpose and placed three detectors at angles of 140-degree, 154-degree, and 180-degree to the source. The EGS4 software package has been chosen as a substrate for volumetric percentage determination with a 3\% error for all flow regimes. In 2020, Sattari and his colleagues were able to simulate three common flow regimes in the volumetric percentage of $5-90 \%$ using a structure containing a detector and a cesium-137 source [2]. They performed two independent GMDH neural networks to detect volume percentages and flow regimes. In the beginning, they passed the photon spectrum extracted from the detector through a Savitzky-Golay filter to eliminate the existing high-frequency noise, then extracted 7 time-domain characteristics from this spectrum to give them as input of the neural network. This approach could eventually achieve the type of flow regimes and volume percentage prediction with a root mean square error of less than 1.11. Some studies in recent years have shown that gamma radiation can be used as a technique to detect these internal deposits in oil and gas pipelines. Oliviera et al. used a structure with a NaI detector and a source of cesium-137 to inspect the scale deposited pipe in 2015 [3]. In the discussed approach, the detector and the source move simultaneously in $0.5 \mathrm{~cm}$ increments. At each stop, the detector records the gamma spectrum passed through the pipe for one minute. The results showed that the presence and thickness of scale in the pipe could be predicted. In reference [4], the researchers simulated three flow regimes in different volumetric percentages and scale thickness inter the pipe; they were able to classify flow regimes with not very high accuracy using SVM neural network and predicted volumetric percentages with an RMSE of less than 3.67 using the MLP neural network. In addition, in a similar study [5], an attempt was made to predict the scale thickness in the pipe independent of the flow regime and volume percentage using the RBF neural network with an RMSE of less than 0.22. Radiation multiphase flowmeters and the applications of artificial intelligence in them can be found in other studies that are available in references [6-15]. Oil and gas pipelines may become internally fouled and have devastating effects. These deposits can reduce the internal diameter, reduce the equipment life cycle, reduce efficiency, and, ultimately, increase costs [16]. The scale deposited in a pipeline is depicted in Figure 1. 


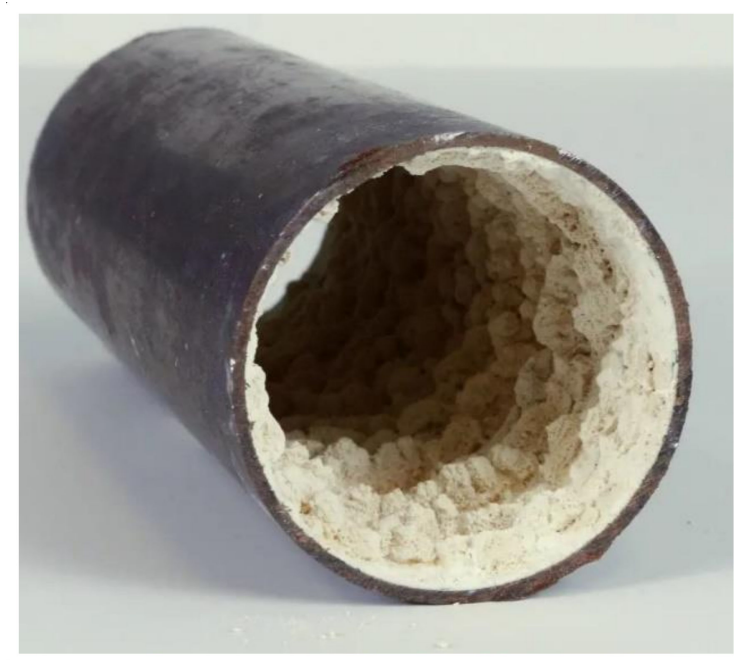

Figure 1. An example of a scale formed in a pipeline.

\section{Simulation Setup}

The modeling of the detection system in this study was performed through version $X$ of Monte Carlo N-Particle Code (MCNPX) [17]. The schematic view of the mentioned detection system is shown in Figure 2. As is apparent, the two-phase flow and the scale formed inside the steel pipe are in the middle, and the dual-energy source and two NaI detectors at a 45-degree angle to each other are on the other side. In this schematic, the stratified flow is considered as an example.

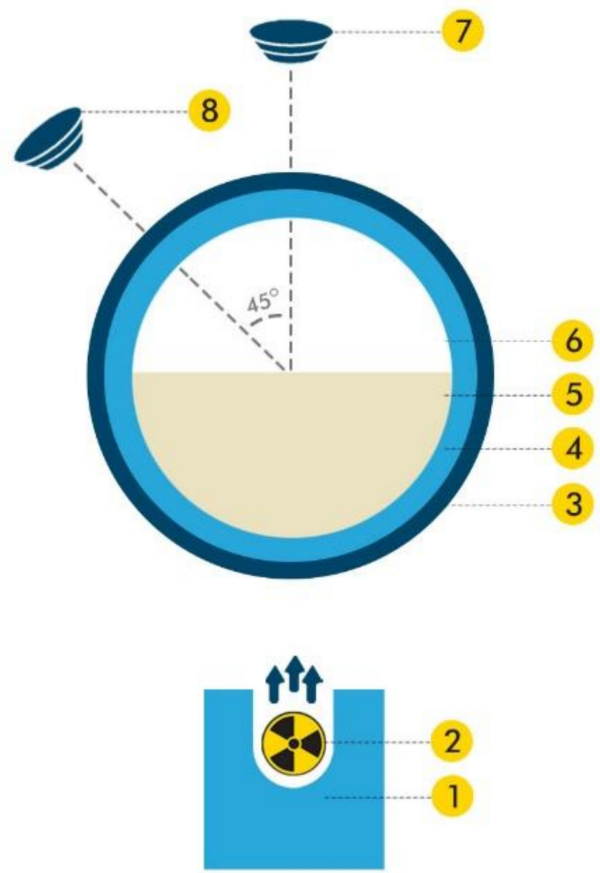

Figure 2. Simulated detection system: 1—shield, 2-dual energy source, 3—steel pipe, 4-scale layer, 5-liquid phase, 6-gas phase, 7-transmission detector, 8-scattering detector.

In the source part, a dual-energy gamma source, including radioisotopes of Cesium-137 and Barium-133 was used, which radiate $0.662 \mathrm{MeV}$ and $0.356 \mathrm{MeV}$, respectively. In the proposed structure, scattered and transmitted photons are received by two $25.4 \mathrm{~mm} \times 25.4 \mathrm{~mm}$ $\mathrm{NaI}$ detectors. The detector, which is responsible for recording transmitted photons, was located on the other side of the pipe just opposite the photon transmitter source. The 
other detector, which is responsible for receiving the scattered photons, was located at a 45-degree angle with the hypothetical line connecting the center of the pipe to the transmission detector. The pipe was considered in this simulation is made of steel with an inner diameter of $20 \mathrm{~cm}$. The scale on the inner wall of the pipe was intended as a circular symmetrical layer of $\mathrm{BaSO}_{4}$ with different thicknesses. Three types of flow regimes with annular, stratified, and homogeneous names were simulated in volume percentages between $10 \%$ to $85 \%$ with steps of $15 \%$ and in seven different scale thicknesses. In our previous work [18], the structure discussed in this article had been validated by several experiments. The obtained detector responses were compared in experimental and simulation. The results showed a good agreement between the simulated results and the experimental data. The uttermost relative difference between the experimental data and simulated data for the detector response was $2.2 \%$. The actual working conditions were dynamic; however, the reference points for flowmeter training were fixed and can be considered static, so experiments and simulations were performed in static conditions. These fixed points were used for flowmeter training to determine the volume fraction and to detect flow regimes in multiphase flowmeters in real conditions. Swift gamma-ray neutron active analysis was considered for quantitative analysis for swift, non-intrusive and online measurements of multiphasic seawater/gas/oil flows in [19]. In this research, all simulations have been considered in static conditions but have been used in real conditions. In [20], conceivable use of transmitted and scattered gamma radiation detection for the characterization of produced water from offshore oil wells has been evaluated. The simulated flow regimes are illustrated in Figure 3. Figure 4 depicts the spectra recorded for three flow regimes with a scale thickness of $2 \mathrm{~cm}$ and a void fraction of $55 \%$ in both detectors.

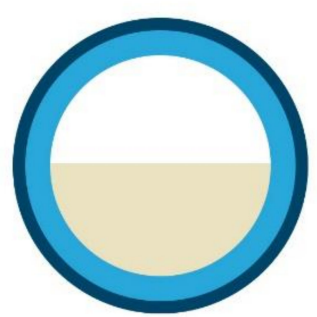

(a)

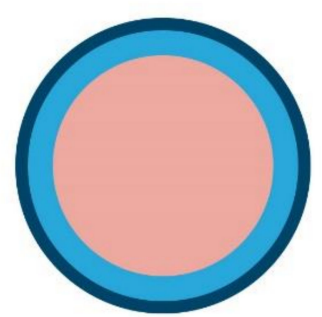

(b)

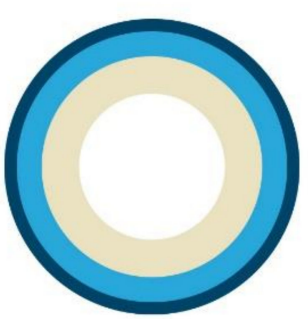

(c)

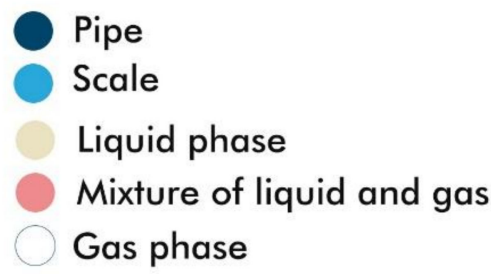

Gas phase

Figure 3. simulated flow regimes (a) stratified (b) homogeneous (c) annular.
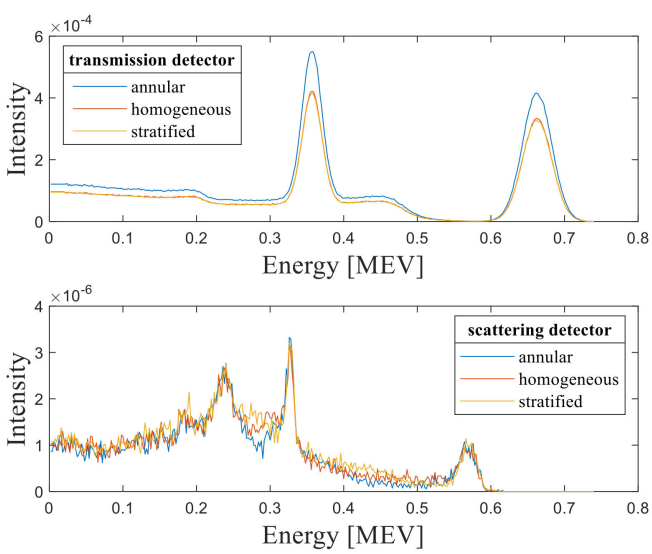

Figure 4. Signal recorded by the transmission and scattering detectors for all three simulated regimes at $2 \mathrm{~cm}$ scale thickness and $55 \%$ void fraction.

\section{Feature Extraction}

Feature extraction is a process of defining a set of features that aims to reduce the signal size, but this size reduction should preserve the properties of the signal and make it 
even more suitable for interpretation. There are several methods for extracting the features of signals. For instance, extraction of characteristics in the frequency domain, extraction of characteristics in the time domain, combined mode of extraction of characteristics in the time-frequency domain, and even other creative methods. Sattari et al. Examined time characteristics that used a creative method to select the characteristics of skewness, kurtosis, and 4th order moment as efficient characteristics [21]. The same creative method was used in the research of Hosseini et al. to select the appropriate frequency characteristics [22]. There are several methods to determine the effective and appropriate properties of the signal, for example, in [2], researchers used the GMDH neural network to determine the effective signal properties. They used the network's self-organizing feature as a tool for feature selection. Feature extraction method using wavelet transform has also been considered by many researchers $[23,24]$. By extracting the approximate and the details of the received signals, they extract the characteristic features of the signal. Correlation analysis methods have also been studied to determine suitable characteristics in other studies [25]. Nevertheless, the gap in their research was that they did not consider the scale thickness of the inner pipe. In this study, inspired by previous research [21], three time features of skewness, kurtosis, and 4th order moment were extracted as follows:

- $\quad 4$ th order moment:

$$
m_{4}=\frac{1}{N} \sum_{n=1}^{N}[x(n)-m]^{4}, \quad m=\frac{1}{N} \sum_{n=1}^{N} x(n)
$$

- skewness:

$$
g_{1}=\frac{m_{3}}{\sigma^{3}}, \quad m_{3}=\frac{1}{N} \sum_{n=1}^{N}\left[x_{n}-m\right]^{3}, \quad \sigma^{2}=\frac{1}{N} \sum_{n=1}^{N}\left(x_{n}-m\right)^{2}
$$

- $\quad$ kurtosis:

$$
g_{2}=\frac{m_{4}}{\sigma^{4}}
$$

\section{MLP Neural Network}

In the past few decades, various advanced computational approaches, e.g., finite element, numerical linear algebra, statistics, numerical analysis, tensor analysis, and artificial intelligence, have been applied in various fields of study, such as fluid mechanic engineering [26-34], chemical engineering [35-41], electrical and computer engineering [42-72], petrochemical engineering [73-77], petroleum engineering [78-92], mathematics and physics [93-102], and environmental engineering [103-107]. The ANN has been demonstrated to be the most potent technique for classification and prediction among the aforementioned computational methods.

Perceptron is a kind of neural network in terms of computational unit. In fact, perceptron is a single-layer neural network; a multilayer perceptron is called a neural network. Taking of real values of input vectors and calculating a linear composition of these inputs are perceptron's duties. If the result value is less than the threshold value, the perceptron output will be -1 and, otherwise, will be 1 . The following equation determines the perceptron output $[108,109]$ :

$$
y=f\left(\sum_{i=1}^{u} w_{i} x_{i}+w_{i}\right)
$$

The page is divided into two parts if the perceptron has two inputs $x_{1}$ and $x_{2}$ and the equation of the dividing line is defined as follows:

$$
w_{1} x_{1}+w_{2} x_{2}+w_{0}=0
$$


In the $\mathrm{n}$-dimensional space of instances, perceptron is thought-outed as a hyperplane. Perceptron only learns instances that are linearly separable so that it can completely divide the instances into two parts by a hyperplane and apply the values of -1 to one side and 1 to the other side. Obtaining the values of perceptron weights is the goal of training it so that perceptron produces the real value of training instances. Perceptron is taught according to the following algorithm:

1. Weights get random values

2. For each training instance, perceptron is applied. If the samples are misjudged, the perceptron weight values are corrected.

3. Are all trainings evaluated correctly?

4. Yes, the end of the algorithm.

5. No, back to step 2 .

When the network is single-neuron, it loses the ability to implement nonlinear functions. Multilayer perceptron networks (MLP) are very useful and can be offered as a solution because they perform nonlinear mapping with high accuracy, which is considered as the main solution in many engineering problems. MLP is a type of feed-forward network; the output is calculated directly from the input without any feedback. In the MLP network, the neuron model consists of a nonlinear activation function. Nonlinearity, continuity, and derivability at all points are some of the features that an activation function should have. If the activation function is not nonlinear, the network performance will be reduced to the level of monolayer perceptron.

\section{Result and Discussion}

In this paper, two separate artificial multilayer perceptron neural networks are designed to classify the type of flow regimes and predict the volume percentages independent of the thickness of the scale in the pipe. The inputs of both networks are the characteristics introduced in the previous section- extracted from the recorded signals from both the TD and the SD. In total, 126 simulations were performed in this study, of which about 70\% (88 samples), 15\% (19 samples), and 15\% (19 samples) were used for training, validation, and testing data, respectively. The structure of the classifier network to identify the type of flow regimes is shown in Figure 5. To show the performance of this network, the confusion matrix is plotted for train, validation, and test data in Figure 6. It is very important to say that the output of this network consists of three numbers, 1, 2, and 3, which represent the annular, stratified, and homogeneous regimes, respectively. In addition, the thresholds for the output of this network are defined in such a way that if the output was between 0.5 to 1.5 , the output number would be equal to 1 , if the output number was between 1.5 to 2.5 , the output would return to 2 and if the output was between 2.5 to 3.5, the network declares a homogeneous regime in the output.

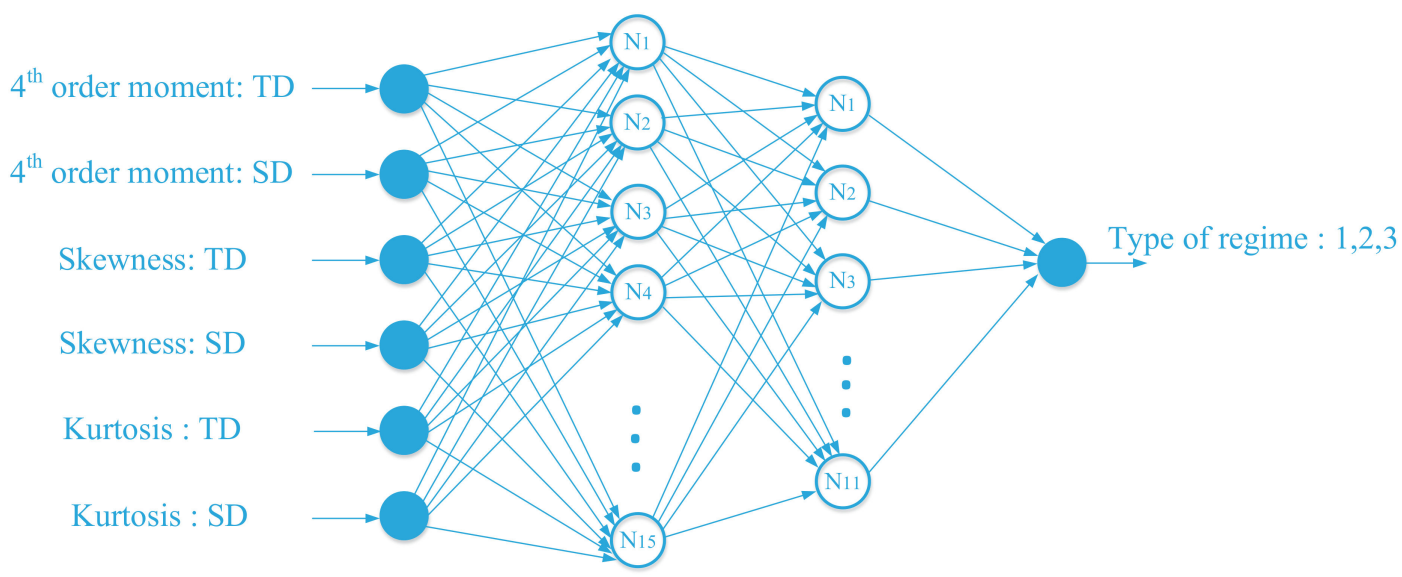

Figure 5. Structure of classifier network. 


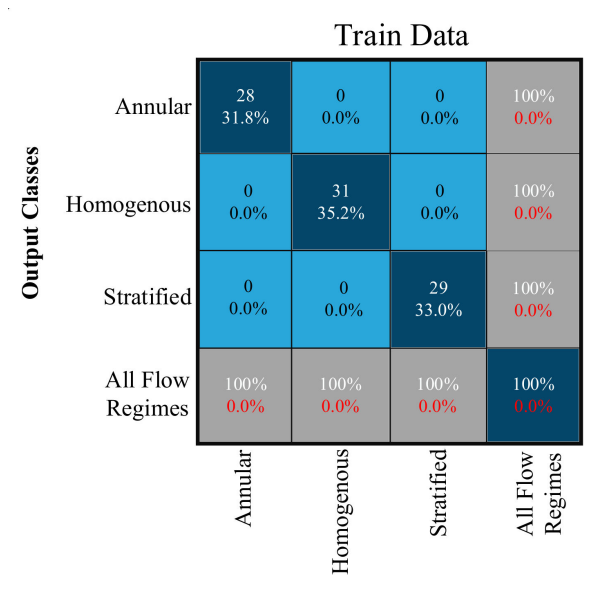

Target Classes

(a)

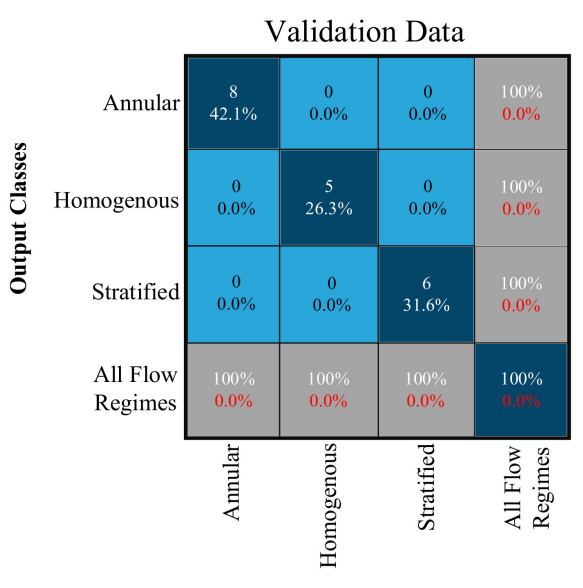

Target Classes

(b)

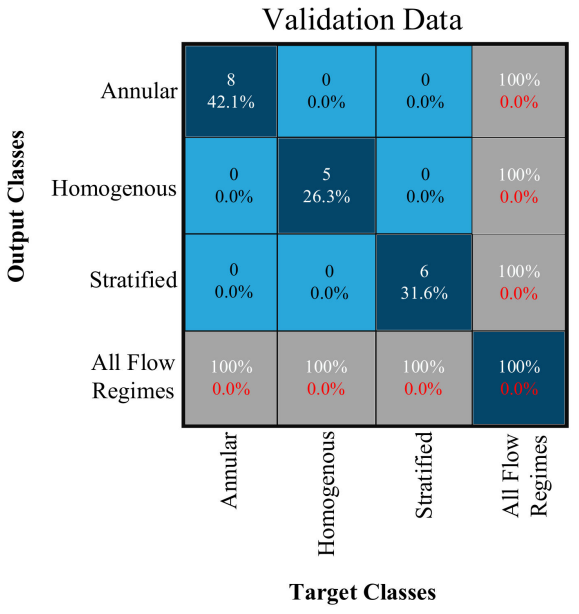

(c)

Figure 6. Confusion matrix to show the classification network performance for (a) training, (b) validation and (c) testing data.

Another network has been implemented with the aim of predicting volume percentages; the structure of this network is shown in Figure 7. To obtain the optimal network structure, various networks with one, two, three, and four hidden layers and with the different number of neurons in each layer and different activating functions including linear, log-sigmoid (Logsig), Heaviside, and hyperbolic tangent sigmoid (Tansig) were examined; which is the most optimal structure for both classifier and predictor networks is shown in Table 1. This table includes the number of input neurons, the number of hidden layers, and the number of neurons in each hidden layer, as well as the type of activation function and the number of the epoch. To show the performance of the predictor network, a fitting diagram and the error diagram were used for the three data sets of training, validation, and testing (Figure 8). The fitting diagram shows both the desired output and the output of the designed network on a graph. The more the two diagrams match, the higher the accuracy of the designed network. The error diagram also shows the difference between the desired output and the network output for each of the data. One of the most important parameters in determining the accuracy of predictor networks is determining the accuracy measurement criteria. In this research, criteria named root mean square error (RMSE) and mean relative error (MRE), with the following equations, have been applied. The calculated values for these criteria are listed in Table 2.

$$
\begin{gathered}
M R E \%=100 \times \frac{1}{N} \sum_{j=1}^{N}\left|\frac{X_{j}(\text { Exp })-X_{j}(\text { Pred })}{X_{j}(\text { Pred })}\right| \\
\text { RMSE }=\left[\frac{\sum_{j=1}^{N}\left(X_{j}(\text { Exp })-X_{j}(\text { Pred })\right)^{2}}{N}\right]^{0.5}
\end{gathered}
$$

where $\mathrm{N}$ is the amount of data and ' $\mathrm{X}($ Exp $)$ ' and ' $\mathrm{X}$ (Pred)' stands for the experimental and predicted (ANN) values, respectively. 


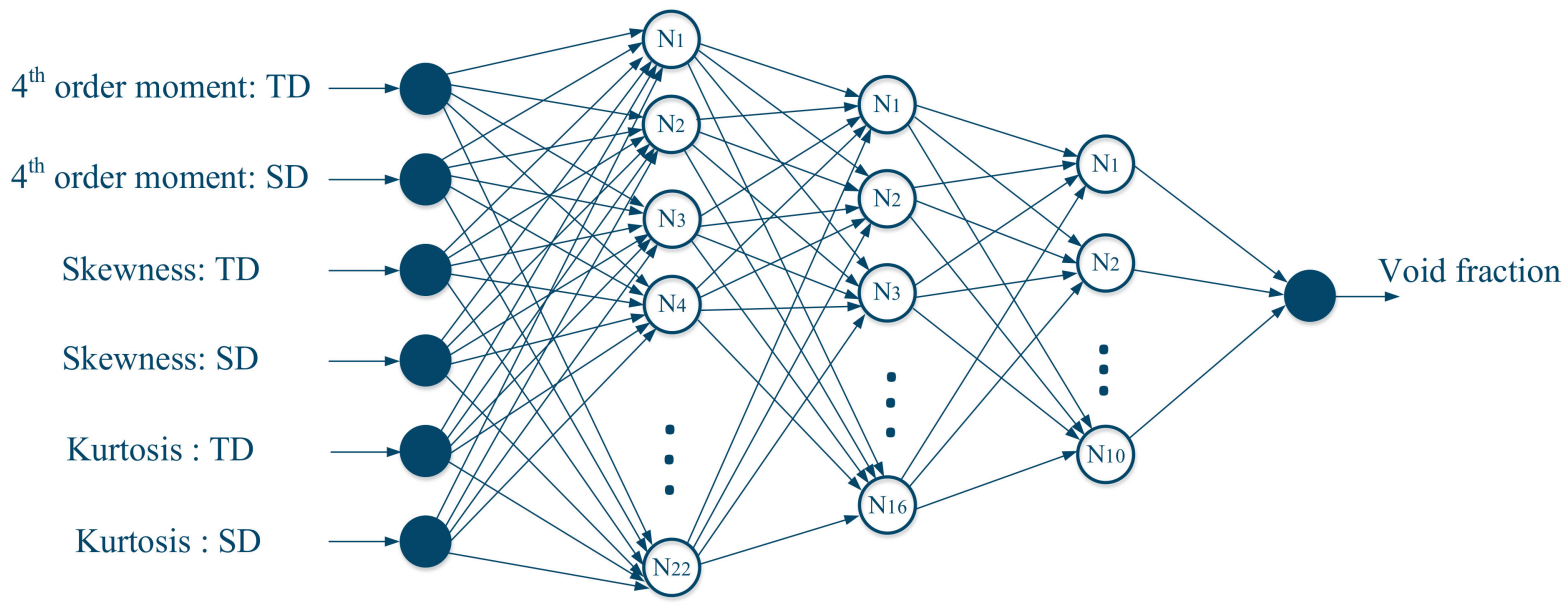

Figure 7. Structure of predictor network.

Table 1. The characteristics of designed networks.

\begin{tabular}{lcc}
\hline \multirow{2}{*}{ ANN Kind } & \multicolumn{2}{c}{ MLP } \\
\cline { 2 - 3 } & Classifier & Predictor \\
\hline No. of neurons in input layer & 6 & 6 \\
\hline No. of neurons in the 1st hidden layer & 15 & 22 \\
\hline No. of neurons in the 2nd hidden layer & 11 & 16 \\
\hline No. of neurons in the 3rd hidden layer & - & 10 \\
\hline No. of neurons in the output layer & 1 & 1 \\
\hline No. of epoch & 680 & 530 \\
\hline Activation function used for each hidden neuron & Tansig & Tansig \\
\hline
\end{tabular}

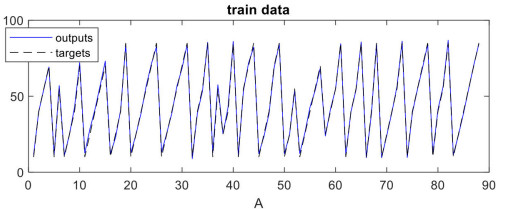

RMSE $=1.5624, \mathrm{MRE} \%=5.6931$

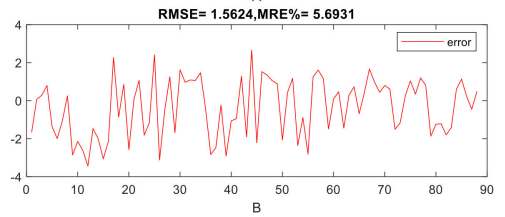

(a)
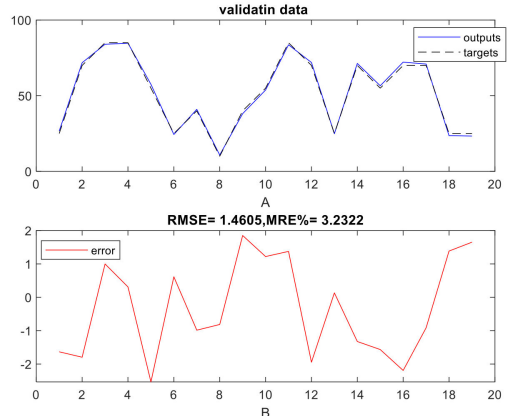

(b)
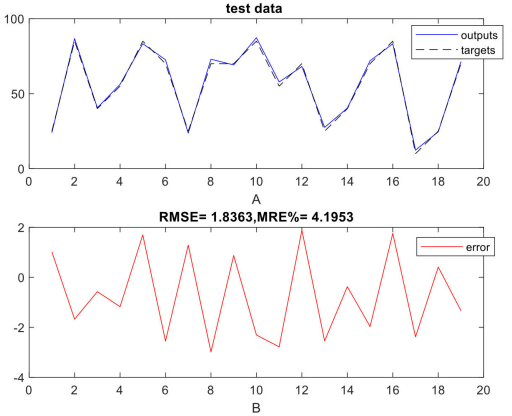

(c)

Figure 8. Fitting and error diagram to show the predictor network performance for (a) training, (b) validation and (c) testing data.

Table 2. Calculated errors for the predictor network.

\begin{tabular}{ccl}
\hline RMSE & MRE\% & Data Set \\
\hline 1.56 & 5.69 & Train \\
\hline 1.46 & 3.23 & Validation \\
\hline 1.83 & 4.19 & Test \\
\hline
\end{tabular}




\section{Conclusions}

The present paper, through a creative structure based on radiation, offers an approach for flow pattern and volumetric percentage detection in scale-laden petroleum pipelines. For this purpose, a structure consisting of a dual-energy gamma source, two NaI detectors, and a pipe, to simulate different flow regimes at different volume percentages, as well as to model the scale thickness inside the pipe, was simulated using the Monte Carlo code. After completing all simulations and data collection, to better interpret the collected data, the feature extraction technique in the time-domain was used. The extracted features, which include 4th order moment, skewness, and kurtosis, were considered as neural network inputs. Two designed MLP neural networks were able to fully classify flow regimes and predict volume percentages with an RMSE of less than 1.84, respectively.

Author Contributions: Conceptualization, S.M.A. and I.M.N.; methodology, A.K.A., K.S.N.; software, A.K.A., S.N.; investigation, K.S.N.; data curation, E.N.; writing-original draft preparation, S.M.A., J.W.G.G., E.E.-Z., S.N.; writing-review and editing, H.M.A.-D.; visualization, J.W.G.G.; supervision, E.N.; funding acquisition, I.M.N., A.K.A., E.E.-Z., K.S.N., H.M.A.-D. All authors have read and agreed to the published version of the manuscript.

Funding: We acknowledge support by the Open Access Publication Fund of the Thueringer Universitaetsund Landesbibliothek Jena. This work was supported by the Taif University Researchers Supporting Project grant number (TURSP-2020/266), of Taif University, Taif, Saudi Arabi. This paper has been supported by the RUDN University Strategic Academic Leadership Program. The research was performed at the expense of the subsidy for the state assignment in the field of scientific activity for 2021 No FSRW-2020-0014.

Institutional Review Board Statement: Not applicable.

Informed Consent Statement: Not applicable

Data Availability Statement: Data are contained within the article

Conflicts of Interest: The authors declare no conflict of interest.

\section{References}

1. Åbro, E.; Khoryakov, V.A.; Johansen, G.A.; Kocbach, L. Determination of Void Fraction and Flow Regime Using a Neural Network Trained on Simulated Data Based on Gamma-Ray Densitometry. Meas. Sci. Technol. 1999, 10, 619.

2. Sattari, M.A.; Roshani, G.H.; Hanus, R. Improving the Structure of Two-Phase Flow Meter Using Feature Extraction and GMDH Neural Network. Radiat. Phys. Chem. 2020, 171, 108725. [CrossRef]

3. Oliveira, D.F.; Nascimento, J.R.; Marinho, C.A.; Lopes, R.T. Gamma Transmission System for Detection of Scale in Oil Exploration Pipelines. Nucl. Instruments Methods Phys. Res. Sect. A Accel. Spectrometers Detect. Assoc. Equip. 2015, 784, 616-620. [CrossRef]

4. Roshani, M.; Phan, G.T.; AliP, J.M.; Roshani, G.H.; Hanus, R.; Duong, T.; Corniani, E.; Nazemi, E.; KalmounE, M. Evaluation of Flow Pattern Recognition and Void Fraction Measurement in Two Phase Flow Independent of Oil Pipeline's Scale Layer Thickness. Alex. Eng. J. 2021, 60, 1955-1966. [CrossRef]

5. Alamoudi, M.; Sattari, M.; Balubaid, M.; Eftekhari-Zadeh, E.; Nazemi, E.; Taylan, O.; Kalmoun, E. Application of Gamma Attenuation Technique and Artificial Intelligence to Detect Scale Thickness in Pipelines in Which Two-Phase Flows with Different Flow Regimes and Void Fractions Exist. Symmetry 2021, 13, 1198. [CrossRef]

6. Roshani, G.H.; Nazemi, E.; Feghhi, S.A.; Setayeshi, S. Flow Regime Identification and Void Fraction Prediction in Two-Phase Flows Based on Gamma Ray Attenuation. Measurment 2015, 62, 25-32. [CrossRef]

7. Nazemi, E.; Feghhi, S.A.H.; Roshani, G.H.; Peyvandi, R.G.; Setayeshi, S. Precise Void Fraction Measurement in Two-Phase Flows Independent of the Flow Regime Using Gamma-ray Attenuation. Nucl. Eng. Technol. 2016, 48, 64-71. [CrossRef]

8. Karami, A.; Roshani, G.H.; Salehizadeh, A.; Nazemi, E. The Fuzzy Logic Application in Volume Fractions Prediction of the Annular Three-Phase Flows. J. Nondestruct. Evaluation 2017, 36, 35. [CrossRef]

9. Roshani, M.; Sattari, M.A.; Ali, P.J.M.; Roshani, G.H.; Nazemi, B.; Corniani, E.; Nazemi, E. Application of GMDH Neural Network Technique to Improve Measuring Precision of a Simplified Photon Attenuation Based Two-Phase Flowmeter. Flow Meas. Instrum. 2020, 75, 101804. [CrossRef]

10. Sætre, C.; Tjugum, S.-A.; Johansen, G.A. Tomographic Segmentation in Multiphase Flow Measurement. Radiat. Phys. Chem. 2014, 95, 420-423. [CrossRef]

11. Karami, A.; Roshani, G.H.; Khazaei, A.; Nazemi, E.; Fallahi, M. Investigation of Different Sources in Order to Optimize the Nuclear Metering System of Gas-Oil-Water Annular Flows. Neural Comput. Appl. 2018, 32, 3619-3631. [CrossRef] 
12. Mosorov, V.; Zych, M.; Hanus, R.; Sankowski, D.; Saoud, A. Improvement of Flow Velocity Measurement Algorithms Based on Correlation Function and Twin Plane Electrical Capacitance Tomography. Sensors 2020, 20, 306. [CrossRef] [PubMed]

13. Salgado, C.; Brandão, L.; Conti, C.; Salgado, W. Density Prediction for Petroleum and Derivatives by Gamma-Ray Attenuation and Artificial Neural Networks. Appl. Radiat. Isot. 2016, 116, 143-149. [CrossRef]

14. 14. Roshani, M.; Ali, P.J.M.; Roshani, G.H.; Nazemi, B.; Corniani, E.; Phan, N.H.; Tran, H.-N.; Nazemi, E. X-Ray Tube with Artificial Neural Network Model as a Promising Alternative for Radioi-Sotope Source in Radiation Based Two Phase Flowmeters. Appl. Radiat. Isot. 2020, 164, 109255.

15. Biswal, J.; Pant, H.; Goswami, S.; Samantray, J.; Sharma, V.; Sarma, K. Measurement of Flow Rates of Water in Large Diameter Pipelines Using Radiotracer Dilution Method. Flow Meas. Instrum. 2018, 59, 194-200. [CrossRef]

16. Candeias, J.; de Oliveira, D.; dos Anjos, M.; Lopes, R. Scale Analysis Using X-Ray Microfluorescence and Computed Radiography. Radiat. Phys. Chem. 2014, 95, 408-411. [CrossRef]

17. Pelowitz, D.B. MCNP-X TM User's Manual; Version 2.5.0. LA-CP-05e0369; Los Alamos National, Laboratory: Los Alamos, NM, USA, 2005.

18. Nazemi, E.; Roshani, G.H.; Feghhi, S.A.H.; Setayeshi, S.; Zadeh, E.E.; Fatehi, A. Optimization of a Method for Identifying the Flow Regime and Measuring Void Fraction in a Broad Beam Gamma-Ray Attenuation Technique. Int. J. Hydrog. Energy 2016, 41, 7438-7444. [CrossRef]

19. Meric, I.; Johansen, G.A.; Mattingly, J.; Gardner, R. On the Ill-Conditioning of the Multiphase Flow Measurement by Prompt Gamma-Ray Neutron Activation Analysis. Radiat. Phys. Chem. 2014, 95, 401-404. [CrossRef]

20. Holstad, M.B.; Johansen, G.A. Produced Water Characterization by Dual Modality Gamma-Ray Measurements. Meas. Sci. Technol. 2005, 16, 1007-1013. [CrossRef]

21. Sattari, M.A.; Roshani, G.H.; Hanus, R.; Nazemi, E. Applicability of time-domain feature extraction methods and artificial intelligence in two-phase flow meters based on gamma-ray absorption technique. Measurement 2021, 168, 108474. [CrossRef]

22. Hosseini, S.; Roshani, G.; Setayeshi, S. Precise Gamma Based Two-Phase Flow Meter Using Frequency Feature Extraction and only One Detector. Flow Meas. Instrum. 2020, 72, 101693. [CrossRef]

23. Siavash, H.; Taylan, O.; Abusurrah, M.; Akilan, T.; Nazemi, E.; Eftekhari-Zadeh, E.; Bano, F.; Roshani, G.H. Application of Wavelet Feature Extraction and Artificial Neural Networks for Improving the Performance of Gas-Liquid Two-Phase Flow Meters Used in Oil and Petrochemical Industries. Polymers 2021, 13, 3647.

24. Balubaid, M.; Sattari, M.A.; Taylan, O.; Bakhsh, A.A.; Nazemi, E. Applications of Discrete Wavelet Transform for Feature Extraction to Increase the Accuracy of Monitoring Systems of Liquid Petroleum Products. Math. 2021, 9, 3215. [CrossRef]

25. Abdulrahman, B.; Sattari, M.A.; Taylan, O.; Nazemi, E. Application of Feature Extraction and Artificial Intelligence Techniques for Increasing the Accuracy of X-Ray Radiation Based Two Phase Flow Meter. Mathematics 2021, 9, 1227.

26. Roshani, G.H.; Feghhi, S.A.H.; Mahmoudi-Aznaveh, A.; Nazemi, E.; Adineh-Vand, A. Precise volume fraction prediction in oilwater-gas multiphase flows by means of gamma-ray attenuation and artificial neural networks using one detector. Measurement 2014, 51, 34-41. [CrossRef]

27. Saberinejad, H.; Keshavarz, A.; Payandehdoost, M.; Azmoodeh, M.R.; Batooei, A. Numerical study of heat transfer performance in a pipe partially filled with non-uniform porous media under Ltne Condition. Int. J. Num. Methods Heat Fluid Flow 2018, 28, 1845-1865. [CrossRef]

28. Nazemi, E.; Feghhi, S.; Roshani, G.; Setayeshi, S.A.; Peyvandi, R.G. A radiation-based hydrocarbon two-phase flow meter for estimating of phase fraction independent of liquid phase density in stratified regime. Flow Meas. Instrum. 2015, 46, 25-32. [CrossRef]

29. Roshani, G.H.; Nazemi, E.; Feghhi, S.A.H. Investigation of using 60Co source and one detector for determining the flow regime and void fraction in gas-liquid two-phase flows. Flow Meas. Instrum. 2016, 50, 73-79. [CrossRef]

30. Rouhi, S.; Xiros, N.; Sadeqi, S.; Ioup, J.; Sultan, C.; VanZwieten, J. CFD validation of the thermodynamic model of a compressed gaseous hydrogen storage tank. Proceeding of 5-6th Thermal and Fluids Engineering Conference (TFEC), Virtual, 26-28 May 2021.

31. Roshani, G.H.; Nazemi, E.; Roshani, M.M. Flow regime independent volume fraction estimation in three-phase flows using dual-energy broad beam technique and artificial neural network. Neural Comput. Appl. 2016, 28, 1265-1274. [CrossRef]

32. Roshani, G.; Nazemi, E.; Roshani, M. Usage of two transmitted detectors with optimized orientation in order to three phase flow me-tering. Measurement 2017, 100, 122-130. [CrossRef]

33. Roshani, G.; Nazemi, E. Intelligent densitometry of petroleum products in stratified regime of two phase flows using gamma ray and neural network. Flow Meas. Instrum. 2017, 58, 6-11. [CrossRef]

34. Roshani, G.; Nazemi, E.; Roshani, M. Intelligent recognition of gas-oil-water three-phase flow regime and determination of volume fraction using radial basis function. Flow Meas. Instrum. 2017, 54, 39-45. [CrossRef]

35. Du, X.; Tian, W.; Pan, J.; Hui, B.; Sun, J.; Zhang, K.; Xia, Y. Piezo-phototronic effect promoted carrier separation in coaxial P-N junctions for self-powered photodetector. Nano Energy 2022, 92, 106694. [CrossRef]

36. Karami, A.; Roshani, G.H.; Nazemi, E.; Roshani, S. Enhancing the performance of a dual-energy gamma ray based three-phase flow meter with the help of grey wolf optimization algorithm. Flow Meas. Instrum. 2018, 64, 164-172. [CrossRef]

37. Roshani, G.H.; Roshani, S.; Nazemi, E.; Roshani, S. Online measuring density of oil products in annular regime of gas-liquid two phase flows. Measurement 2018, 129, 296-301. [CrossRef] 
38. Cai, T.; Dong, M.; Liu, H.; Nojavan, S. Integration of hydrogen storage system and wind generation in power systems under demand response program: A novel P-robust stochastic programming. Int. J. Hydrogen Energy 2022, 47, 443-458. [CrossRef]

39. Roshani, G.; Hanus, R.; Khazaei, A.; Zych, M.; Nazemi, E.; Mosorov, V. Density and velocity determination for single-phase flow based on radiotracer technique and neural networks. Flow Meas. Instrum. 2018, 61, 9-14. [CrossRef]

40. Charchi, N.; Li, Y.; Huber, M.; Kwizera, E.A.; Huang, X.; Argyropoulos, C.; Hoang, T. Small mode volume plasmonic film-coupled nanostar resonators. Nanoscale Adv. 2020, 2, 2397-2403. [CrossRef] [PubMed]

41. Roshani, G.; Nazemi, E.; Roshani, M. Identification of flow regime and estimation of volume fraction independent of liquid phase density in gas-liquid two-phase flow. Prog. Nucl. Energy 2017, 98, 29-37. [CrossRef]

42. Roshani, S.; Roshani, S. Two-Section Impedance Transformer Design and Modeling for Power Amplifier Applications. Appl. Comput. Electromagn. Soc. J. 2017, 32, 1042-1047.

43. Lalbakhsh, A.; Alizadeh, S.M.; Ghaderi, A.; Golestanifar, A.; Mohamadzade, B.; Jamshidi, M.B.; Mandal, K.; Mohyuddin, W. A design of a dual-band bandpass ?lter based on modal analysis for modern communication systems. Electronics 2020, 9, 1770. [CrossRef]

44. Liu, X.; Zheng, W.; Mou, Y.; Li, Y.; Yin, L. Microscopic 3D reconstruction based on point cloud data generated using defocused images. Measurement and Control 2021, 54, 1309-1318. [CrossRef]

45. Pirasteh, A.; Roshani, S.; Roshani, S. Compact microstrip lowpass filter with ultrasharp response using a square-loaded mod-ified T-shaped resonator. Turk. J. Electr. Eng. Comput. Sci. 2018, 26, 1736-1746. [CrossRef]

46. Ramtin, A.R.; Nain, P.; Menasche, D.S.; Towsley, D.; de Souza e Silva, E. Fundamental scaling laws of covert ddos attacks. Performance Evaluation 2021, 151, 102236. [CrossRef]

47. Roshani, S.; Roshani, S. A compact coupler design using meandered line compact microstrip resonant cell (MLCMRC) and bended lines. Wireless Networks 2021, 27, 677-684. [CrossRef]

48. Ma, Z.; Zheng, W.; Chen, X.; Yin, L. Joint embedding VQA model based on Dynamic Word Vector. PeerJ Comput. Sci. 2021, 7, e353. [CrossRef] [PubMed]

49. Lalbakhsh, A.; Lotfi Neyestanak, A.A.; Naser-Moghaddasi, M. Microstrip hairpin bandpass filter using modified Minkowski fractal-shape for suppression of second harmonic. IEICE Trans. Electron. 2012, E95-C, 378-381. [CrossRef]

50. Pourghebleh, B.; Aghaei Anvigh, A.; Ramtin, A.R.; Mohammadi, B. The importance of nature-inspired meta-heuristic algorithms for solving virtual machine consolidation problem in Cloud Environments. Cluster Comput. 2021, 24, 2673-2696. [CrossRef]

51. Seyedi, M.; Taher, S.A.; Ganji, B.; Guerrero, J. A hybrid islanding detection method based on the rates of changes in voltage and active power for the Multi-Inverter Systems. IEEE Trans. Smart Grid 2021, 12, 2800-2811. [CrossRef]

52. Roshani, S.; Roshani, S. Design of a very compact and sharp bandpass diplexer with bended lines for GSM and LTE applica-tions. AEU. Int. J. Electron. Commun. 2019, 99, 354-360. [CrossRef]

53. Wang, K.; Wang, H.; Li, S. Renewable quantile regression for streaming datasets. Knowledge-Based Systems 2022, $235,107675$. [CrossRef]

54. Lalbakhsh, A.; Mohamadpour, G.; Roshani, S.; Ami, M.; Roshani, S.; Sayem, A.S.M.; Alibakhshikenari, M.; Koziel, S. Design of a compact planar transmission line for miniaturized rat-race coupler with harmonics suppression. IEEE Access 2021, 9 , 129207-129217. [CrossRef]

55. Roshani, S.; Roshani, S.; Zarinitabar, A. A modified Wilkinson power divider with ultra harmonic suppression using open stubs and lowpass filters. Analog. Integr. Circuits Signal Process. 2019, 98, 395-399. [CrossRef]

56. Wang, K.; Li, S. Robust distributed modal regression for massive data. Comput. Stat. Data Anal. 2021, 160, 107225. [CrossRef]

57. Jamshidi, M.B.; Siahkamari, H.; Roshani, S.; Roshani, S. A compact Gysel power divider design using U-shaped and T-shaped reso-nators with harmonics suppression. Electromagnetics 2019, 39, 491-504. [CrossRef]

58. Jamshidi, M.B.; Roshani, S.; Talla, J.; Roshani, S.; Peroutka, Z. Size reduction and performance improvement of a microstrip Wilkinson power divider using a hybrid design technique. Sci. Rep. 2021, 11, 7773. [CrossRef] [PubMed]

59. Liu, K.; Ke, F.; Huang, X.; Yu, R.; Lin, F.; Wu, Y.; Ng, D.W. Deepban: A temporal convolution-based communication framework for dynamic WBANS. IEEE Trans. Commun. 2021, 69, 6675-6690. [CrossRef]

60. Pirasteh, A.; Roshani, S.; Roshani, S. A modified class-F power amplifier with miniaturized harmonic control circuit. AEU Int. J. Electron. Commun. 2018, 97, 202-209. [CrossRef]

61. Roshani, S.; Roshani, S. Design of a high efficiency class-F power amplifier with large signal and small signal measure-ments. Measurement 2020, 149, 106991. [CrossRef]

62. Lalbakhsh, A.; Jamshidi, M.; Siahkamari, H.; Ghaderi, A.; Golestanifar, A.; Linhart, R.; Talla, J.; Simorangkir, R.B.; Mandal, K. A compact lowpass ?lter for satellite communication systems based on transfer function analysis. AEU-Int. J. Electron. Commun. 2020, 124, 153318. [CrossRef]

63. Nazemi, B.; Rafiean, M. Forecasting House Prices in Iran Using GMDH. Int. J. Hous. Mark. Anal. 2021, 14, 555-568. [CrossRef]

64. Roshani, S.; Roshani, S. Design of a compact LPF and a miniaturized Wilkinson power divider using aperiodic stubs with harmonic suppression for wireless applications. Wireless Networks 2019, 26, 1493-1501. [CrossRef]

65. Lalbakhsh, A.; Afzal, M.U.; Esselle, K. Simulation-driven particle swarm optimization of spatial phase shifters. In Proceedings of the 2016 International Conference on Electromagnetics in Advanced Applications (ICEAA), Cairns, QLD, Australia, 19-23 September 2016. 
66. Hookari, M.; Roshani, S.; Roshani, S. High?efficiency balanced power amplifier using miniaturized harmonics suppressed coupler. Int. J. RF Microwave Comput.-Aided Eng. 2020, 30, e22252. [CrossRef]

67. Lalbakhsh, A.; Afzal, M.U.; Esselle, K.P.; Smith, S.L. Low-cost nonuniform metallic lattice for rectifying aperture near-field of electromagnetic bandgap resonator antennas. IEEE Trans. Antennas Propagation 2020, 68, 3328-3335. [CrossRef]

68. Pirasteh, A.; Roshani, S.; Roshani, S. Design of a miniaturized class F power amplifier using capacitor loaded transmission lines. Frequenz 2020, 74, 145-152. [CrossRef]

69. Lalbakhsh, A.; Afzal, M.U.; Hayat, T.; Esselle, K.P.; Manda, K. All-metal wideband metasurface for near-?eld transformation of medium-to-high gain electromagnetic sources. Sci. Rep. 2021, 11, 1-9.

70. Lotfi, S.; Roshani, S.; Roshani, S.; Gilan, M.S. Wilkinson power divider with band-pass filtering response and harmonics suppression using open and short stubs. Frequenz 2020, 74, 169-176. [CrossRef]

71. Lalbakhsh, A.; Ghaderi, A.; Mohyuddin, W.; Simorangkir, R.B.V.B.; Bayat-Makou, N.; Ahmad, M.S.; Lee, G.H.; Kim, K.W. A Compact C-Band Bandpass Filter with an Adjustable Dual-Band Suitable for Satellite Communication Systems. Electronics 2020, 9, 1088. [CrossRef]

72. Hookari, M.; Roshani, S.; Roshani, S. Design of a low pass filter using rhombus-shaped resonators with an analyticallc equivalent circuit. Turkish J. Electr. Eng. Comput. Sci. 2020, 28, 865-874. [CrossRef]

73. Yadollahi, A.; Nazemi, E.; Zolfaghari, A.; Ajorloo, A.M. Application of artificial neural network for predicting the optimal mixture of radiation shielding concrete. Progress Nuclear Energy 2016, 89, 69-77. [CrossRef]

74. Roshani, M.; Phan, G.; Faraj, R.H.; Phan, N.H.; Roshani, G.H.; Nazemi, B.; Corniani, E.; Nazemi, E. Proposing a gamma radiation based intelligent system for simultaneous analyzing and detecting type and amount of petroleum by-products. Neural Eng. Technol. 2021, 53, 1277-1283. [CrossRef]

75. Wang, Y.; Cheng, H.; Hu, Q.; Liu, L.; Jia, L.; Gao, S.; Wang, Y. Pore structure heterogeneity of Wufeng-Longmaxi Shale, Sichuan Basin, China: Evidence from gas physisorption and multifractal geometries. J. Petroleum Sci. Eng. 2022, 208, 109313. [CrossRef]

76. Roshani, M.; Phan, G.; Roshani, G.H.; Hanus, R.; Nazemi, B.; Corniani, E.; Nazemi, E. Combination of X-ray tube and GMDH neural network as a nondestructive and potential technique for measuring characteristics of gas-oil-water three phase flows. Measurement 2021, 168, 108427. [CrossRef]

77. Xu, G.F. Numerical simulation and factor analysis of petrochemical pipe erosion-corrosion failure. In IOP Conference Series: Materials Science and Engineering; IOP Publishing: Bristol, UK, 2016; Volume 129, p. 012033.

78. Dolgii, I.E. Methods to enhance oil recovery in the process of complex field development of the Yarega oil and titanium deposit. $J$ Min. Inst. 2017, 231, 263-297.

79. Aleksandrov, A.N.; Kishchenko, M.A.; Van, T.N. Simulating the formation of wax deposits in wells using electric submersible pumps. In Advances in Raw Material Industries for Sustainable Development Goals; CRC Press: London, UK, 2021 ; pp. $283-295$.

80. Nguyen, V.T.; Rogachev, M.K.; Aleksandrov, A.N. A new approach to improving efficiency of gas-lift wells in the conditions of the formation of organic wax deposits in the dragon field. J. Pet. Explor. Prod. Technol. 2020, 10, 3663-3672. [CrossRef]

81. Sandyga, M.S.; Struchkov, I.A.; Rogachev, M.K. Formation damage induced by wax deposition: Laboratory investigations and modeling. J. Pet. Explor. Prod. Technol. 2020, 10, 2541-2558. [CrossRef]

82. Sultanbekov, R.; Islamov, S.; Mardashov, D.; Beloglazov, I.; Hemmingsen, T. Research of the influence of marine residual fuel composition on sedimentation due to incompatibility. J. Mar. Sci. Eng. 2021, 9, 1067. [CrossRef]

83. Kashnikov, Y.A.; Ashikhmin, S.G.; Kukhtinskii, A.E.; Shustov, D.V. The relationship of fracture toughness coefficients and geophysical characteristics of rocks of hydrocarbon deposits. J. Min. Inst. 2020, 1, 241. [CrossRef]

84. Karpikov, A.V.; Aliev, R.I.; Babyr, N.V. An analysis of the effectiveness of hydraulic fracturing at YS1 of the Northern field. In IOP Conference Series: Materials, Science and Engineering; IOP Publishing: Bristol, UK, 2020; Volume 952, p. 012036.

85. Belonogov, E.V.; Korovin, A.Y.; Yakovlev, A.A. Increase of the injectivity coefficient by dynamic development of injection wells. J. Min. Inst. 2019, 1, 238.

86. Grigorev, M.B.; Tananykhin, D.S.; Poroshin, M.A. Sand management approach for a field with high viscosity oil. J. Appl. Eng. Sci. 2020, 18, 64-69. [CrossRef]

87. Shagiakhmetov, A.M.; Podoprigora, D.G.; Terleev, A.V. The study of the dependence of the rheological properties of gelforming compositions on the crack opening when modeling their flow on a rotational viscometer. Period. Tche Quimica 2020, 17, 933-939. [CrossRef]

88. Galkin, S.V.; Kochnev, A.A.; Zotikov, V.I. Predictive assessment of the effectiveness of radial drilling technology for the Bashkir production facilities of the Perm Territory fields. J. Min. Inst. 2019, 1, 238.

89. Molchanov, A.A.; Ageev, P.G. Implementation of new technologies is a reliable way of extracting residual reserves of hydrocarbon deposits. J. Min. Inst. 2017, 1, 227.

90. Prischepa, O.M.; Nefedov, Y.V.; Kochneva, O.E. Raw material base of hard-to-extract oil reserves of Russia (Matéria-prima base de reservas de óleo de difícil extração da Rússia). Periodico TCHE Quimica 2020, 17, 915-924.

91. Morenov, V.; Leusheva, E.; Martel, A. Investigation of the fractional composition effect of the carbonate weighting agents on the rheology of the clayless drilling mud. Int. J. Eng. 2018, 31, 1152-1158.

92. Nikitin, M.N.; Saychenko, L.A. The rheological properties of abnormally viscous oil. Pet. Sci. Technol. 2018, 36, 136-140. [CrossRef]

93. Ghanbari, B. Abundant exact solutions to a generalized nonlinear Schrödinger equation with local fractional derivative. Math. Methods Appl. Sci. 2021, 44, 8759-8774. [CrossRef] 
94. Kharazmi, O.; Jahangard, S. A new family of lifetime distributions in terms of cumulative hazard rate function. Commun. Fac. Sci. Univ. Ankara Series A1Math. Stat. 2020, 69, 1-22. [CrossRef]

95. Ghanbari, B. Chaotic behaviors of the prevalence of an infectious disease in a prey and predator system using fractional derivatives. Math. Methods Appl. Sci. 2021, 44, 9998-10013. [CrossRef]

96. Kharazmi, O.; Saadatinik, A.; Jahangard, S. Odd hyperbolic cosine exponential-exponential (OHC-ee) distribution. Annals Data Sci. 2019, 6, 765-785. [CrossRef]

97. Ghanbari, B. On novel nondifferentiable exact solutions to local fractional Gardner's equation using an effective technique. Math Method Appl. Sci. 2020, 44, 4673-4685. [CrossRef]

98. Rashidisabet, H.; Thomas, P.J.; Ajilore, O.; Zulueta, J.; Moore, R.C.; Leow, A. A systems biology approach to the Digital behaviorome. Curr. Opin. Syst. Biol. 2020, 20, 8-16. [CrossRef]

99. Nabti, A.; Ghanbari, B. Global Stability Analysis of a fractional SVEIR epidemic model. Math. Methods Appl. Sci. 2021, 44, 8577-8597. [CrossRef]

100. Rezaei, T.; Aslmarand, S.M.; Snyder, R.; Khajavi, B.; Alsing, P.M.; Fanto, M.; Ahn, D.; Miller, W.A. Experimental realization of Schumacher's information geometric Bell inequality. Physics Lett. A 2021, 405, 127444. [CrossRef]

101. Ghanbari, B. A fractional system of delay differential equation with nonsingular kernels in modeling hand-foot-mouth disease. Adv. Diff. Eq. 2020, 2020. [CrossRef]

102. Ghanbari, B. On approximate solutions for a fractional prey-predator model involving the Atangana-Baleanu derivative. Adv. Diff. Eq. 2020, 2020, 1-20. [CrossRef]

103. Tian, J.; Liu, Y.; Zheng, W.; Yin, L. Smog prediction based on the deep belief - BP neural network model (DBN-BP). Urban Climate 2022, 41, 101078. [CrossRef]

104. Daryayehsalameh, B.; Nabavi, M.; Vaferi, B. Modeling of CO2 capture ability of [bmim][bf4] ionic liquid using connectionist smart paradigms. Environ. Technol. Innov. 2021, 22, 101484. [CrossRef]

105. Zhao, X.; Xia, H.; Pan, L.; Song, H.; Niu, W.; Wang, R.; Li, R.; Bian, X.; Guo, Y.; Qin, Y. Drought Monitoring over Yellow River Basin from 2003-2019 Using Reconstructed MODIS Land Surface Temperature in Google Earth Engine. Remote Sens. 2021, 13, 3748. [CrossRef]

106. Etimita, O.O.; Beka, F.T. Heavy mineral analysis of Eocene Sands and sandstones of Nanka Formation, Cenozoic Niger delta petroleum province. Geol. Ecol. Landsc. 2019, 4, 251-256. [CrossRef]

107. Singh, B.; Sihag, P.; Parsaie, A.; Angelaki, A. Comparative analysis of artificial intelligence techniques for the prediction of infiltration process. Geol. Ecol. Landsc. 2020, 5, 109-118. [CrossRef]

108. Taylor, J.G. Neural Networks and Their Applications; John Wiley \& Sons Ltd.: Brighton, UK, 1996.

109. Gallant, A.R.; White, H. On Learning the Derivatives of an Unknown Mapping with Multilayer Feedforward Networks. Neural Networks 1992, 5, 129-138. [CrossRef] 